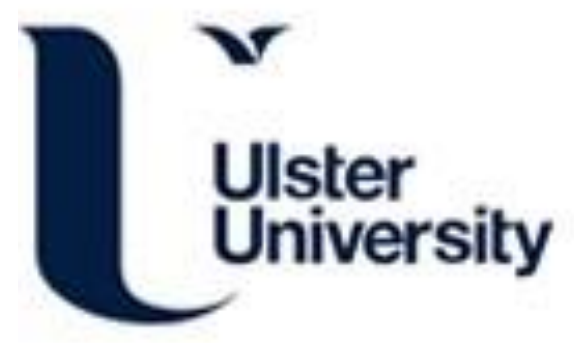

\title{
'Our children can see that we aren't the only wee school in the countryside': Can Shared Teachers offer solutions to the challenges facing rural primary schools in a divided society?
}

Bates, J., \& McCully, A. (2020). 'Our children can see that we aren't the only wee school in the countryside': Can Shared Teachers offer solutions to the challenges facing rural primary schools in a divided society? Irish Educational Studies, 40(1), 129-146. https://doi.org/10.1080/03323315.2020.1800502

Link to publication record in Ulster University Research Portal

Published in:

Irish Educational Studies

Publication Status:

Published online: 06/08/2020

DOI:

10.1080/03323315.2020.1800502

\section{Document Version}

Author Accepted version

\section{General rights}

Copyright for the publications made accessible via Ulster University's Research Portal is retained by the author(s) and / or other copyright owners and it is a condition of accessing these publications that users recognise and abide by the legal requirements associated with these rights.

\section{Take down policy}

The Research Portal is Ulster University's institutional repository that provides access to Ulster's research outputs. Every effort has been made to ensure that content in the Research Portal does not infringe any person's rights, or applicable UK laws. If you discover content in the Research Portal that you believe breaches copyright or violates any law, please contact pure-support@ulster.ac.uk. 
Our children can see that we aren't the only wee school in the countryside: Can Shared Teachers offer solutions to the challenges facing rural primary schools in a divided society?

Jessica Bates (Correspondence author), UNESCO Centre, School of Education, Ulster University, Coleraine Campus, Cromore Road, Coleraine, N Ireland, BT52 1SA.

Email: j.bates@ulster.ac.uk ORCiD: 0000-0002-0854-2205 Twitter: @Jessica_Bates

Alan McCully, UNESCO Centre, School of Education, Ulster University.

ORCiD: 0000-0002-4083-1824

Dr Jessica Bates is a Lecturer at the School of Education, Ulster University, Northern Ireland. She carries out research in Education and Library and Information Science. Her current education research focuses on education, sustainable schools, and participatory research that gives school communities a voice in local school provision in Northern Ireland.

Dr Alan McCully is an Honorary Research Fellow in the UNESCO Centre, Ulster University, contributing to its work on Education, Conflict and Peacebuilding. As an educator he has engaged with interventions in history and social studies seeking to contribute to better community relations in Northern Ireland. Particularly, his research has focused on the interface between history learned in schools and that encountered in families and communities, and on the pedagogy of teaching sensitive and controversial issues. 


\begin{abstract}
This paper examines the experience of Shared Teachers (STs) who were employed on temporary contracts across school partnerships designed to enrich and integrate the educational experiences of children in primary schools in rural and religiously diverse areas in Northern Ireland, as part of a specific Shared Education Programme. In a society emerging from conflict, where Shared Education is advocated both to improve the quality of education and contribute to more positive community relations, this paper critically explores the strengths and limitations of using a ST initiative to develop inter-school collaboration. There were clear educational benefits in sharing resources, planning and curricular enrichment but the potential to affect positive community relations was often limited. STs were used for routine tasks within individual partnership schools, rather than normalising shared experience where pupils are educated together. STs lacked the institutional support necessary to challenge the cultural and social mores embedded within a divided society.
\end{abstract}

\title{
Keywords
}

Shared Education; Shared Teachers; Rural schools; Northern Ireland; Post-conflict; Sustainable schools 
Our children can see that we aren't the only wee school in the countryside: Can Shared Teachers offer solutions to the challenges facing rural primary schools in a divided society?

\section{Introduction}

This paper focuses on two challenges facing education policy makers in Northern Ireland (NI): to contribute to community cohesion in an often segregated post-conflict society, and to provide quality, sustainable education to a widely dispersed rural population. Both relate to the structure and organisation of school provision and addressing each has implications for the other. NI, a divided society, operates two largely separate schooling systems, catering for pupils from Protestant and Catholic backgrounds (Smith and Hansson 2015). Historically, there has been a prevalence of small primary schools with more than half having composite classes (mainly of two year groupings); $89 \%$ of these schools are situated in rural areas (Perry et al. 2017). In recent decades both aspects of policy have come under scrutiny. In a divided society, it is argued that being educated separately does little to contribute to greater social cohesion and reconciliation (Smith 2014). Additionally, small rural schools lack an economy of scale and struggle to provide pupils with their full educational entitlement (Department of Education 2009).

Since 2007, NI Executive policy has prioritised Shared Education - the creation of more systemic links between schools - as a way of rationalising educational services and fostering stronger inter-community links. The research described here draws on the Primary Integration and Enriching Education (PIEE) initiative, designed to develop closer cooperation between small, rural primary schools (SRPS) across the sectarian divide. The researchers carried out a detailed investigation on all aspects of PIEE's work (Hunter et al. 2011). Here, the aim is to examine one dimension, the joint employment of an additional teacher with at least one other rural school in a local partnership, as a strategy to enrich the curriculum and strengthen interschool relationships. Research to date on Shared Education in NI has concentrated predominantly on urban partnerships or settings (for example, Duffy and Gallagher 2017; Borooah and Knox 2013, Young 2013). Furthermore, there has been no in-depth examination of the Shared Teacher (ST) role. This paper concentrates on the experiences of the 10 STs in PIEE. It examines their potential to improve educational sustainability and community relations in rural areas where, in separate schools, they are likely to be regarded as "belonging" to one community or the other, and be treated accordingly. Its innovation comes from 
discerning impact in a NI context, and highlighting lessons for other post-conflict societies, and rural communities elsewhere.

\section{Education and conflict in NI context}

Since its inception in 1921 the NI state has largely educated Catholics and Protestants separately, the former in schools under the control of the Catholic Church (Maintained schools) and the latter in schools run directly by the state (Controlled schools) (Akenson 1970). Currently, despite the emergence of a small, Integrated school sector (Smith 2001), separation remains significant. Department of Education for Northern Ireland (DENI) figures for 2017/18 show that $91 \%$ of pupils in the primary school sector attended either a Controlled or a Catholic Maintained school1. Almost half of Northern Ireland's schoolchildren (49\%) were being taught in schools where $80 \%$ or more of the pupils are of the same religion2 3. Separation extends to teacher employment. Milliken's research (Milliken et al. 2020) indicates that $93 \%$ of the staff employed in Catholic Maintained primary schools had attended Catholic primary schools, and $85 \%$ of the staff employed in Controlled schools had been educated in that sector.

Following the outbreak of conflict in 1968 ("the Troubles"), commentators have explored the causal relationship between educational separation and sectarian violence (see Richardson 2011). The argument is advanced that each school sector helps shape both young people's sense of religious identification and their cultural identity, thus perpetuating divisions (Murray 1985).

Educational separation has been challenged in three ways: through curricular initiatives common to all schools; by seeking to establish cross-community links between schools; and by creating common schools with a purposive emphasis on integration both in numerical composition and ethos. This study focuses on school partnerships across the divide. The cases for and against curricular initiatives (see Richardson 2011) and Integrated schools (see Hansson et al. 2013) have relevance to this study but limited space prevents even a brief consideration here.

\footnotetext{
${ }^{1}$ According to DENI school enrolment data for 2017/18 there are 817 primary schools in Northern Ireland; 367 Catholic Maintained schools, 266 Controlled schools, 23 Grant Maintained Integrated schools, 22 Controlled Integrated schools, 28 Other Maintained schools, and 11 Voluntary schools, https://www.educationni.gov.uk/articles/school-enrolments-overview.

2 Based on the 673 primary schools that provided data on the religious breakdown of pupils for 2017/18, https://www.education-ni.gov.uk/articles/school-enrolments-overview. 32011 Census figures show that $42 \%$ of the NI population described themselves as Protestant or Other Christian, $41 \%$ as Catholic, and $17 \%$ as No religion / Not Stated.
} 
Early cross-community encounters between young people were premised on the idea that prejudice was born out of ignorance of the other. Contact was promoted largely through informal activity but, subsequently, DENI provided financial support to school partnerships on a voluntary basis. However, many partnerships were deemed superficial, unlikely to engage pupils in explicit consideration of difference and reliant on the good will of individual teachers, rather than being embedded in practice (O'Connor et al. 2002). Through time, approaches became more sophisticated and structured, often employing contact and social identity theories as their underpinning base with research demonstrating that, under optimum conditions, contact can contribute to more harmonious relationships (Niens et al. 2003; Hughes et al. 2012).

\section{Shared Education in NI}

Since 2000, financial and political factors have contributed to curtailing the growth of Integrated education. Statutory support continues for schools that wish to "transform" and become Integrated 4 (see Hansson et al. 2013) but over-capacity within the school system has made it difficult, financially, to justify the creation of new schools. There has been a renewed focus on taking cross-community contact forward through the concept of Shared Education. This has had the support of the two dominant political parties, the Democratic Unionist Party and Sinn Fein, both of which place strong emphasis on providing local resources for their respective electoral constituencies (Gardner 2016, 250-252).

Thus, Shared Education, amply supported by philanthropic funding, has emerged as the NI Assembly's solution by enabling pupils to attend existing predominantly single-religion schools but emphasising systemic sharing between schools. Within the Sharing Works policy document (DENI 2015, 15), Shared Education is defined as involving 'the sustained provision of opportunities for children and young people from different communities, as well as social and economic, backgrounds, to learn together'. Gallagher $(2016,362)$ asserts that it promotes 'collaborative networks of schools in local areas, with pupils and teachers moving between schools to take classes and share experience.' Emphasis is on sustained interaction of staff and pupils and on students learning together (Hewstone and Hughes 2015).

An emergent body of scholarly literature regarding Shared Education reflects positively on current policy directions, arguing that it raises academic standards and contributes to greater social cohesion (Borooah and Knox 2015; Duffy and Gallagher 2015). However, there is also 
concern at both political and academic levels (Smith and Hansson 2015). Fundamentally, how far can cultural barriers be lowered when pupils continue to identify through institutions located within single community spaces? Also, in regard to sustainability, how can enhanced school links be maintained once external funding, additional to day-to-day government expenditure on education, is exhausted? As we will discuss subsequently, these issues are particularly pertinent in rural areas. Is Shared Education actually embedding a culture of shared classes or is implementation more fragmented?

PIEE was one of three Shared Education Programmes (SEPS) funded through the International Fund for Ireland (IFI) and Atlantic Philanthropies (AP) between 2007 and 2013. A combined evaluation was conducted (RSM McClure Watters 2014) but this does not specifically explore the 'ST' element of PIEE. Elsewhere, Hughes and Loader (2015) examine contact, friendship and difference in two Shared Education partnerships in the Queen's University Belfast (QUB) SEP. Duffy and Gallagher (2015) focus on evolving collaborative practices in a three-school post-primary QUB SEP partnership. The evaluation of the Fermanagh SEP (Pro.Ed Consulting 2013) addresses STs but relates to the sharing of existing teaching staff across partnership schools whereas in PIEE new (temporary) ST posts were created. Here we provide a detailed examination of the implementation of the PIEE ST model and its implications for school collaboration in conflict and post-conflict contexts and rural settings.

According to Sharing Works (DENI 2015, 17) sharing occurs by 'pupils coming together from different sectors for curriculum based education' and through cooperation between 'shared teaching and non-teaching staff.' No detailed guidance is provided. PIEE focused entirely on SRPS in the North Eastern Education and Library Board (NEELB). Its aim was to:

set out to develop cross-community partnerships of primary schools in close proximity to each other, providing opportunities for pupils to take part in activities with pupils from other schools in the area, including shared classes. In practice this involved establishing and supporting 11 partnerships, (made up of 28 schools, 25 of which had less than 105 pupils) to work in an increasingly collaborative way at organisational, staff and pupil level over the four year period.

(http://www.neelb.org.uk/schools/piee/ [This web site no longer exists as the project ended in 2013])

In 2012/13 nine PIEE partnerships employed ten STs. The objectives of the shared teacher component were to: further develop the partnering ethos; organise and timetable shared 
classes within partnerships schools; and to further develop community links (NEELB, Shared teachers: Advice and Guidance for Principals and Teachers [document no longer available], see Hunter et al. 2014 for an elaboration on the ST dimension).

\section{Collaboration}

Literature on school collaboration tends to focus on the school, parents and pupils, i.e. home-school relations (Svanbjörnsdóttir et al. 2016); school-community relationships (Valli et al. 2016); collaboration between teachers within a school (Vangrieken et al. 2015) or teachers and other paraprofessionals such as teaching assistants (Devecchi and Rouse 2010), special education needs staff (Mulholland and O’Connor 2016) or school library staff (McKeever et al. 2017) rather than collaboration between schools. However, there is an emergent policy context in England around school partnership, collaboration and school improvement. Armstrong $(2015,5)$ emphasises the lack of research relating to the impact of inter-school collaboration and 'how different types of collaborative arrangements might vary in effectiveness, sustainability and the kinds of impact they make'. Internationally, interest in shared and integrated education in a conflict / post-conflict context is growing, for example the work of Zembylas (2010) in Cyprus, Payes (2013) and Berger et al. (2015) in Israel / Palestine and Hill (2011) in Bosnia-Herzegovina.

Work on collaboration between schools in NI draws on network theory, social constructivism and social learning theory. While usually applied at an individual level, Duffy and Gallagher (2015) argue that knowledge sharing, collaboration and organisational learning can take place where there is effective knowledge sharing within and between schools. Over time 'deep collaboration' and a sustained school partnership should lead to the development of a community of practice.

Research literature indicates that inter-school collaboration brings positive outcomes for teachers/staff, pupils, and the wider community. Such benefits at school/staff level include: sharing professional expertise and good practice (Hunter et al. 2012; Perry 2011; Carlisle and Hughes 2013; Connolly et al. 2019); developing new staff networks and relationships (Hunter et al. 2012); sharing resources, e.g. equipment, learning resources, staff (Hunter et al. 2012; Connolly et al. 2019) and 'delivering more for less' (Perry 2011). Possible benefits for pupils include extending or widening curricular their options/opportunities (Todman et al. 2009; Perry 2011); and bringing them together for shared activities and shared classes, including online learning (Hunter et al. 2012; Connolly et al. 2019). In terms of the wider community, previous 
research has identified the benefit of building cross-community relationships (Hunter et al. 2012).

Undoubtedly, there are also challenges related to developing inter-school relationships. These include a mix of practical or logistical, administrative/bureaucratic, and cultural issues at school/inter-school level. Challenges referenced in the existing literature include: impact on staff workload and time (Todman et al. 2009; Hunter et al. 2012); increased administrative load / increased bureaucracy (Hunter et al. 2012); logistical and timetabling issues (Hunter et al. 2012; Perry 2011; Carlisle and Hughes 2013); and curricula alignment (Carlisle and Hughes 2013). A lack of funding and financial / budgetary issues e.g. relating the cost of transport was identified by Hunter et al. 2012; and Carlisle and Hughes (2013). Social and inter-personal challenges of bringing together those from different community backgrounds have been highlighted in Hunter et al. 2012. Culturally Perry (2011) identified the reluctance of schools with different ethoses or cultures to collaborate and also that a competitive environment, where local schools are competing with each other for pupils, can also have a negative impact on good working relations.

\section{The PIEE project and the rural dimension}

Of the 817 primary schools in Northern Ireland, $460(56 \%)$ are designated as rural (Department of Education NI 2017/18 data5). The provision of SRPS is guided by Schools for the Future: A Policy for Sustainable Schools (DENI 2009). This sets out six criteria, with associated indicators, which relate to links to the local community, educational experience, enrolments, financial position, school leadership and management, and accessibility. It emphasises that through 'meaningful collaboration' across the education system children can experience and explore diversity and interdependence and thereby live together in mutual respect as equal members of society.

NI is not unique in facing the challenge of viability of small schools in rural areas. In England, Todman et al. (2009) cite barriers facing small, rural schools including recruiting head teachers and offering a range of services beyond what is required at a statutory level. One facet of collaboration they examine is 'executive headship', when a single head teacher is shared between schools. Muijs (2015) advocates that 'collaboration may be especially valuable for rural schools' in helping address the issues of lack of resources or scale and in raising

5 https://www.education-ni.gov.uk/articles/school-enrolments-overview. 
standards. Šūpule and Søholt (2019), studying how to maintain good rural schools under conditions of depopulation in Latvia and Norway, find there is scope for innovative solutions and manoeuvrability, along with greater community participation in decision-making.

In NI, in addition to inter-community tensions, there is a serious sustainability issue linked to the existence of parallel schools within rural communities. Despite an independent review of school provision (Bain 2006) drawing attention to 'too many schools', more recently, in 2014-15, 'there were 71,000 (20 per cent of capacity) surplus school places' (Northern Ireland Audit Office 2015, 2). In 2017/18, that figure was 63,063 (17.5\%) with one third of rural primary schools below threshold6. Shared Education offers little to mitigate against surplus places, and schools within partnerships may actually be competing with each other for survival (Perry 2011; Hunter et al. 2011; Carlisle and Hughes 2013).

\section{Methodology}

The research aims to examine the shared teacher role within PIEE and its potential for contributing to better community relations and educational sustainability in rural areas.

It utilised a mixed-method approach to data collection involving:

- $\quad$ semi-structured interviews with every ST in the PIEE programme; and

- $\quad$ surveys of teachers and principals in every PIEE school that had a ST.

This mixed-method approach allowed for data to be collected from multiple perspectives (shared teachers, principals, and other teachers in the schools) at broadly the same point in time. Timing was important - data needed to be collected towards the end of the school year to ensure that the research would capture respondents' fullest experiences of the role. This meant that researchers did not have the luxury of undertaking the data collection in phases where one phase informed the next. A strength of mixed-method research nonetheless is in the triangulation of findings. The value of such an approach is in 'producing converging evidence', which should be 'more compelling than might have been produced by any single method alone' (Yin 2006, p. 41).

$6 \mathrm{https}: / / \mathrm{www}$. education-

ni.gov.uk/sites/default/files/publications/education/Annual\%20Report\%20on\%20Area\%20Planning.pdf 
In the 2012/13 school year, nine of eleven PIEE partnerships employed an ST and one employed two STs, giving a total of ten across nine partnerships. All ten were interviewed at one of the schools in which they worked and each gave their consent to be interviewed and digitally audio-recorded. Interviews ranged in duration from twenty-three to seventy-two minutes, and the average interview length was thirty-eight minutes. These were semi-structured interviews, with each interviewee asked the same questions, but the format was sufficiently flexible for interviewees to raise new issues if they wanted to. The interviews sought to examine how the STs perceived their role; how it related to their prior teaching experience; what their responsibilities and relationships were in each partnership school; any particular challenges they encountered; the training they received; and their reflections after a year in post. The interview data was thematically analysed using Braun and Clarke's (2006) six-stage framework for analysis. Both a priori and emergent codes were developed in order to deepen understanding of STs' experiences and perspectives and what can be learned from this. Coding was undertaken both manually and using the open-source qualitative data analysis software Weft QDA (pressure.to/qda).

Questions on the wider teacher and principal surveys, conducted online (using the online social survey software Qualtrics), were broadly similar and focused on the role of the ST, activities during the school year and whether the PIEE partnership was sustainable once funding ended. The principal survey included some additional management questions. The motivation for implementing the two questionnaires separately was to see if there were any differences between the views of teachers and those of principals in relation to the shared teacher role. In the nine partnerships that had an ST, ninety-two teachers were emailed, and the response rate was $32 \%$. Twenty-three principal surveys were sent out with a response rate of $78 \%$. Data from these surveys were analysed using descriptive statistics.

\section{Findings}

\section{The STs and their roles}

Seven of the STs were female and three were male. While none were newly qualified, the majority did not have extensive teaching experience and could be considered early career teachers: eight had five years or less and of these it was a first contractual post for two who had previously been employed as substitute cover or maternity cover (the other two had seven and twelve years' experience respectively). Seven were from a Catholic background, and three 
from a Protestant background. Five were in a two-school partnership, four were in a threeschool partnership and one was in a four-school partnership.

All ten interviewed had a good understanding of the objectives of PIEE: enriching and integrating education; bringing together SRPS; bringing together teachers and pupils; enabling the sharing of resources and ideas; building relationships in the community, community relations and challenging prejudice; and developing good practice. However, variance was evident in the roles and responsibilities allocated to each teacher. NEELB coordinators believed that, as a pilot, implementation should be flexible, with principals having responsibility for its day to day operation. That said, the main activities of STs can be broken down into three broad categories: individual teaching where they had responsibility for teaching a class within one school or a sub-set of pupil(s) within one school (or worked alongside a class teacher in teaching an individual class/sub-set of pupils from the one school); planning where they had specific time allocated to prepare for their classes or other activities they had been asked by a school principal (or in some cases offered) to undertake; and shared teaching where the ST had responsibility for teaching pupils from two or more of the partnership schools at the same time in the one setting. Differences were identified both in how the STs divided their time between their partnership schools and in their professional engagement. This was partly dependent on role, for example, the extent to which they carried out any shared teaching activities. In the four-school partnership, the ST worked one day a week in each school, with Friday being a floating day to go to any of the schools, or work on planning. In one of the three-school partnerships, the ST worked 1.5 days in each of the schools, with the remaining 0.5 day spent on planning. Thus, in the four and three-school partnerships there was less systematic use of shared teaching. There was more evidence of shared teaching in two of the two-school partnerships. In one, the ST spent half of the week teaching shared classes, sited in both schools, and the other half divided between the two schools individually; and in the other the ST spent two days a week delivering shared classes, again in both schools, with the remaining three days working individually in the two partnership schools.

Overall, the data collected identified the following duties and responsibilities of STs (with different STs fulfilling combinations of different roles, duties and responsibilities):

- teaching individual subject areas within individual schools;

- $\quad$ working specifically with individual pupils deemed to have particular needs;

- having responsibility for a particular class all day (e.g. in a job-share role or principal release); 
- teaching shared classes;

- organising all shared activities between the partnership schools;

- team teaching; and

- covering classes for colleagues.

Bearing in mind that formal shared teaching that brought pupils together in one classroom, taught by the ST, was only part of a bigger picture of the shared activities that could take place within partnerships, the STs were asked approximately what percentage of their time over the school year was spent on shared teaching. As Figure 1 below shows, this ranged from $0 \%$ to $59 \%$.

\section{[INSERT FIGURE 1 HERE]}

Only one of ten STs reported that they spent $50 \%$ or more of their time teaching shared classes. Logistically it was more difficult for the four-school partnership to come together for shared activities and when it did it tended to sub-divide into two two-school groupings. Distance was also a constraining factor. The teaching of shared classes tended to be more sustained (and more manageable) in two-school partnerships located geographically close together. In the partnerships where shared classes were most extensive, every child was participating regularly and shared classes were, in the main, embedded in school routines.

Individually, STs valued what they had gained professionally from the role. Enhanced skills they identified included better organisation and time management. Undoubtedly, there were also significant challenges; for example, different work cultures in different schools, learning to do things the way particular teachers want them done, and building relationships with pupils from multiple year groups and schools.

\section{Enriching and integrating education}

Despite shared classrooms not featuring strongly in several partnerships, all STs felt that they had contributed to enhancing the educational experiences of pupils. The benefits can be broadly categorised under the twin PIEE themes of 'enriching' and 'integrating'. Children gained from having access to the ST, in addition to their class teacher, who might have a different way of teaching or specific expertise in areas of the curriculum not touched by other teachers, and by interacting with children from different religious backgrounds to themselves. Specific ways in which the STs thought pupils benefitted included: 
- $\quad$ learning about difference and mutual respect;

- $\quad$ sharing lessons and learning experiences;

- learning through creative projects and video-conferencing;

- $\quad$ greater variation in the school day;

- $\quad$ meeting children from the nearby locality they would not otherwise have met; and

- $\quad$ meeting other children that they may be with when they move to their post-primary school.

One ST commented that younger children got more from PIEE as they were not aware of the religious difference and, by playing and interacting, this would set them up well for their futures: 'I do think the younger ones hopefully get more out of this project, and hopefully as time goes on it just becomes the norm for them' (Interview 8, Catholic).

Principal and teacher responses emphasised the financial and resource benefits of having an ST, suggesting that often they perceived the presence of the ST as chiefly about benefitting teachers and pupils in their own school. For example, STs, when utilised for cover, confirmed this as beneficial for the teacher being released: 'to spend that time to do things ... they're having an hour to an hour and a half of time where they can go away from their classroom and reflect and plan whatever they need to' (Interview 1, Protestant). Regarding pupil gains one interviewee emphasised curriculum enrichment: 'Every school is lacking in some area and especially smaller schools, there's always going to be maybe sport or music lacking and it's just nice that they are able to adapt the ST role to meet their needs' (Interview 6, Catholic). Another referred to widening horizons: 'their subjects have been enhanced from a different person's perspective or way of teaching' (Interview 1, Protestant). However, shared activities arising from the work of the ST, which included joint sports days, outings, drama productions, and an afterschool club were also clearly seen as important: 'They [pupils] can see, oh we aren't the only wee school in the countryside, they can see there are actually other children' (Interview 1, Protestant).

\section{Differences and divisions}

Sustaining SRPSs was a key element of PIEE but, realistically, it was unlikely to have received funding without a commitment to contribute to better community relations. Many small schools are situated in 'rural interfaces', where sectarian division may be less visible but demarcated social networks are often pronounced, with separate economic, religious, social, 
political, and sporting structures juxtaposed in a small geographical area (Murtagh 2003, pp.214-217). Therefore, building new relationships with the other community can be problematic. Any ST, entering into the Other's territory was likely to experience cultural difference, resulting in some uncertainty, or even discomfort. However, the datum illustrates that STs tended to interpret such occurrences as isolated incidents within their overall experience, and even when they encountered resistance, they did not expect resolution at a systemic level.

In several ST interviews, religious difference, disputes over flags and emblems and sporting differences were mentioned as causing unease. The flying of flags can be a contentious and territorial issue in NI. At a time of community tension around flag flying7, one of the interviewees noted that a small number of the Protestant pupils had not wanted to participate in a particular shared day of activities. When asked if the pupils had talked about this the interviewee said 'no' but that the pupils 'just didn't come to school that day' (Interview 1, Protestant). Another ST mentioned an increase in Union flag paraphernalia in a Controlled school they worked in. When asked about this, the ST replied - 'there's been Union Jack pencil cases and school bags this year and she [the principal] is in a very difficult situation, basically there is very small numbers in the school and they can't afford to lose anybody, so if she's telling the parents no your child can't have that school bag or pencil case, they'll say that's fine I'll take my child somewhere else. It's a difficult tightrope she's walking .... the children aren't perhaps buying these, the parents are buying them and I don't know if it's directed towards me.' This ST went on to describe an incident where, following a shared session, a Catholic parent had complained that their child should not 'be subjected to having these flags present in the classroom' (Interview 8, Catholic).

One ST talked about Controlled schools flying Union flags: 'it was very intimidating but at the same time, that's the way the world is. My background before that, I had bought into Integrated education and Shared Education, but my background as such was very Roman Catholic, GAA8, Irish background, so it was a culture shock definitely' (Interview 5, Catholic). In one school, the ST noted that some pupils were wearing 'Supporting the Orange'

\footnotetext{
7 On 3 December 2012, Belfast City Council voted to limit the days that the Union Flag flies from Belfast City Hall. A series of protests were held by loyalists and unionists across Northern Ireland in response to this. The greatest number of street protests took place in the period directly after the decision relating to the Union Flag at Belfast City Hall, i.e. December 2012 through January 2013.

8 GAA: The Gaelic Athletic Association is a parish / community-based organisation governing the playing of the Gaelic sports (see: http://ulster.gaa.ie/).
} 
wristbands.9(Interview 8, Catholic). The ST did not pass comment but realised that these had been sitting on another teacher's desk for pupils to take. Another ST mentioned the strong liking for the Royal family and for 'red, white and blue' in the Controlled school: 'There are wee things that I notice the difference in the two schools, and it makes me smile just because I'm not used to it, like the kids would draw a lot of the Royal family, whereas I wouldn't be used to any interest in the Royal family from the other school' (Interview 3, Catholic).

Around St Patrick's Day an ST had wanted to do ceili dancing with pupils in her partnership. She was worried that this might be controversial but the principal in the Controlled school had said it was fine. Subsequently, pupils questioned her: 'I just stopped the lesson and said, if anybody would like to watch instead of taking part that's fine, and about five children did choose to just sit and watch and .... that was their choice. They were just a bit unsure about it and felt "maybe this isn't for me", so that was interesting. But then ceili dancing is part of both cultures, but they were asking the question "is this Irish dancing?" (Interview 3, Catholic).

Another ST described an incident involving a sports day for local schools in a community centre in the grounds of a GAA club. Children from the Controlled school had been expected to attend. However, five of the nine children came in with notes and were not allowed to go, presumably because of the event's location (Interview 8, Catholic).

One of the STs mentioned that some girls in the Controlled school had sung 'The Sash'10 in class: 'whenever I was teaching up in [name of school] a couple of weeks ago some of the girls started singing 'The Sash' to me, which is awkward for me, ... I don't want to create any problems for the school up there because I'm from a nationalist background and I can't tell the children do not sing this song. To put this in context, I was asking them to do a presentation in their ICT on their favourite things...., and some of the girls whenever they were doing their presentation, my favourite song is The Sash and my favourite colours are red, white and blue, and ....it's not something that [name of principal] would let them do but I'm feeling really uncomfortable trying to stop it because if I did that they'd be home to their parents saying [ST name] wouldn't let us do that and then it would be in to [name of principal] and that would create a whole mountain of problems for her, but I did make her aware of it and

\footnotetext{
9 Sold or distributed by or on behalf of The Orange Order, a Protestant fraternity organisation (see: https://www.goli.org.uk/product-page/wristband)

10 The Sash is a ballad that commemorates the victory of King William III in Ireland 1690-1691 and is sung at marches of The Orange Order (see: https://www.tripsavvy.com/the-sash-my-father-wore-1542690).
} 
she did come in and have a word with them about it, not in my presence' (Interview 8, Catholic).

The same ST also went on to reflect: 'a few of the older girls and the more able girls in the school who were at the beginning with me were really good and really enthusiastic and they've lost their enthusiasm for working with me, and I don't know if that's because they just don't like me or if they don't like me because they've been told at home. I would hate to think that's the case and I hope it isn't, and I've spoken to the teacher .... They're personally entitled not to like me, but not to like me for what I am is a different thing all together' (Interview 8, Catholic).

This ST recalled another incident that had happened at the school gate: 'I did have an experience, this seems awful but there was a parent up at [name of school], and they were just there to pick up their children after school and I walked passed and she did say to the woman standing beside her, "you'll soon have to bless yourself around here." Now that's certainly something you could do without.' (Interview 8, Catholic).

One ST talked about some of the Protestant pupils not being present when there was a visit to a Catholic church - 'there were visits between schools to local churches and I wouldn't be au fait with the rules of the Orange Order but I think that maybe children going into a Catholic church would reflect badly on, I think that was a big issue at a stage, I know that maybe seven or eight children didn't go .... which you could understand to be honest, you're not going to change things overnight, perceptions as such. But the majority of parents, and the majority of stakeholders have bought into the Shared Education in all three schools, so I don't want to put across that this is a big problem' (Interview 5, Catholic).

One other practice, mentioned by two STs, concerned the wearing of the poppy for Remembrance in Controlled schools: 'If I had have been asked, I would have outlined that no, I couldn't wear one, but at the same time, I appreciated their need to wear one, and I'd no problem with it at all' (Interview 5, Catholic).

Another said: 'I remember at the start thinking, am I expected to? But none of the kids mentioned it either, which I thought some of them were going to say, "[says name], why are you not wearing your poppy?" And I, I had thought to say, "oh I left it at home," or something like that, and then I would've probably turned up the next day wearing one, because I'm not really that bothered, to be honest.... the thing is as a ST, if you're entrenched in your beliefs, then you're probably in the wrong thing to be' (Interview 10, Catholic).

Interestingly, despite such incidents, and not always publicly acknowledging personal difference, STs believed their own background was not a major issue: I don't know if the 
parents of this school know anything about my background, and to be honest I don't really make it known to anybody. They would know which side I'm from, from my own education and my teacher training college and things like that .... but they do know and there's never been anything said about it' (Interview 6, Catholic).

For several, however, a valued outcome of the ST role was learning about the 'other' religious tradition:

'it did make me realise that I didn't know a lot about Protestant religion. I do see differences in the culture actually and that's been a real eye opener and I just have a real appreciation I suppose for that now' (Interview 3, Catholic).

'I don't know if you know the area here, but it's very GAA focused and I am not from that background, so I found that strange to begin with but actually I really enjoy the difference now" (Interview 4, Protestant).

In summary, generally, STs declared themselves comfortable in their day-to-day teaching roles across their partnership schools despite unsettling incidents related to cultural or religious difference occurring when working in schools associated with the 'other' tradition. Taking account of circumstance and personal aptitude, teachers often reacted defensively by subsuming their own cultural identity and by ignoring or tolerating displays of cultural expression, especially when they felt these were directed at them. Nor, when alerted, was there evidence that school managements reacted beyond the level of containment. Personally, when STs encountered difference as part of everyday experience they valued the insight this gave them into the 'other's' practices and beliefs. However, there were no reported instances of them using such incidents, positive or negative, as learning experiences to deepen cultural understanding with pupils or colleagues. In reality, then, working within the social and organisational confines operating in a divided society significantly restricted STs' capacity to be agents of change.

\section{STs and inter-school collaboration}

The benefits in having a ST were strongly voiced by school principals and other teachers, who particularly valued the ST as a link between schools. An overwhelming majority of both principals (94\%) and teachers (86\%) strongly agreed or agreed with the statement: The ST has enhanced relationships between the PIEE partnership schools. Statements from the teacher survey, in relation to the role of the ST included: "[to] encourage good relations 
between our pupils, staff and parents'; 'A shared resource to connect learning between the PIEE schools'; and 'To bring the schools together and to help further build and sustain the partnership.'

The ST interviews concentrated on practical ways in which relationships between schools were strengthened, for example, through having someone who knows what is going on in the partner schools e.g. for planning days together. One ST explained: 'The schools had worked together for three years very closely, but I think my role is to enhance that and be the link, so it could even just be in practical things like transporting resources or communication, just passing a message, but also I think the best thing about the ST is that both sets of kids have ownership of you, so when they come together they're relaxed because they both know [says her name] is ours, and they both feel that way so if I'm leading the session that puts them at ease because they both have ownership of me and see that as something they have in common' (Interview 3, Catholic).

Another ST emphasised the greater sharing of resources between the schools: 'For these two particular schools, it's really beneficial for them ....They can share resources they've got things here that they don't have up there and I know where things are in both schools, I can borrow things' (Interview 8, Catholic).

Inevitably, there were also reported instances of tension between schools, and individuals, not necessarily connected to cultural difference. Overall, across the nine partnerships findings were mixed. Evidence demonstrated that STs made a positive contribution on a day to day basis but their potential to lead a sustainable culture of collaboration and shared community of practice was less clear. It is likely that the nature of ST employment, a one-year temporary post, had implications for teacher status, confidence and training which made it difficult to have greater impact.

\section{Discussion and conclusion}

What emerges from this analysis of the ST role is that its success, or otherwise, in the PIEE context at least, depends on whether the role is viewed primarily as being about sharing a teacher, i.e. a shared resource between SRPS to overcome everyday constraints, or as a shared teacher that offers shared classes and learning activities which also seek to open pupils up to wider community perspectives. As argued below, our findings indicate that the role has been more successful if the former conceptualisation is taken, but considerably less so, if the latter is a goal. Even then, questions remain as to how sustainable the model is when external 
funding is removed and it has to operate within the everyday economic constraints of the education budget.

Our study shows that a ST can enable the sharing of resources and good communications within, and between, schools. SRPS which otherwise could not afford an additional teacher availed of the extra part-time (shared) engagement thus enhancing staff expertise, covering gaps in provision and freeing up colleagues for preparation and other duties. However, overall, while participating schools benefitted from having an extra member of staff, shared teaching across partnerships was quite low. Thus, the work frequently focused on alleviating the day-to-day pressures in each partnership school rather than on a more systemic vision of the partnership's potential. The degree of flexibility as to how partnerships implemented the ST position had implications for the extent to which the role could impact on providing integrating experiences for pupils. The strength of STs was that individual schools could tailor their additional capacity to the schools' own curricular and resource needs (including raising the profile of community relations objectives); whereas a weakness was that often this led to less opportunity for children to actually learn together. This may be adequate in other rural settings but where a stated aim is to promote opportunities for shared learning in post-conflict society more explicit guidance is essential for similar projects in the future. The flexibility in how partnerships utilised a ST also had implications for the somewhat ad hoc approaches to support for the STs. While systematic support, guidance and training were provided by the Educational Board that ran the initiative, when it came to school level support was often uneven.

The PIEE project envisioned partnership going beyond simply making small rural schools more viable. It sought to use the ST to enable genuine shared learning which would enhance pupils' educational experience, including contributing to greater cross-community understanding (either through direct teaching or by freeing up others to share their expertise and also deliver shared sessions). Respondents from partnership schools where there was regular shared teaching were convinced of its value but even here findings indicate that particular conditions should operate if this work is to be fully effective. It is essential from the outset that the ST is recognised as an integral member of each of the schools in which they are employed, with management, administration and communication structures accommodating the particular challenges these teachers face, for example, social integration, the provision of personal workspace facilities, their inclusion in all aspects of professional engagement and addressing cultural difference. Too easily the ST was pigeon-holed as individually responsible for the cross-community dimension, thus limiting other teachers' deeper engagement. STs 
reflected perceptively on their professional and social encounters, especially in the school not of their background, but rarely did they share these with colleagues as starting points for deepening cultural dialogue and understanding within and across staffrooms. To have done so would have required levels of professional skill and confidence, and institutional support, not fully evident within partnership structures.

PIEE's use of the ST concept was an experiment in cross-community school cooperation. As such it was time limited to one year and, realistically, was unlikely to bring about permanent change. However, as regards sustainability, it did raise issues for future viability. The ST approach can only be sustainable when the wider partnership is sustainable; when schools are located in geographical proximity, when children are in regular contact with each other, and where there is dedicated funding, for transport (where this is needed) and training. Crucially, if the ST role is to be truly transformative additional resources must be available to develop cultural understanding and build confidence in relationships at all levels of partnerships. It would be unfair to state that external funding was the only key motivator but principals made it clear that without additional financial resources partnerships would be unable to employ the teacher - and therefore be less likely to maintain and develop cooperation.

Finally, at a policy level this study informs wider concerns about the preservation of small, rural schools and Shared Education, both in Northern Ireland and elsewhere. In regard to the former, the paper argues that STs have the potential to be part of a solution to create sustainable rural schools, even though, currently, the continued pressure for closures seems too determined by issues of financial viability to support innovative solutions (Belfast Telegraph 2019). However, a further tension exists between sustaining small rural schools and promoting Shared Education. The latter, some commentators (Smith and Hansson 2015; Fontana 2016) argue, despite its aspirations to cross-cultural understanding, is likely to preserve existing cultural divisions as it is structured to enable the maintenance of separate schooling. Fontana (2016, 251) maintains that: 'the most fundamental criticism of shared education is that there is no "end game" to sharing and this perpetuates acceptable levels of segregation.' Therefore, before there is a policy commitment to placing STs in rural partnerships further research is required to be confident that sustained, regular cross-community interaction of pupils is socially and financially sustainable and that STs are contributing to greater social cohesion in rural communities.

\section{Acknowledgements}


The authors thank Professor Linda Clarke and Dr Una O'Connor-Bones from the School of Education, Ulster University for their valuable feedback prior to submission.

\section{References}

Armstrong, P. (2015) Effective school partnerships and collaboration for school improvement: a review of the evidence. London: Department of Education. https://assets.publishing.service.gov.uk/government/uploads/system/uploads/attachme nt_data/file/467855/DFE-RR466_-

_School_improvement_effective_school_partnerships.pdf.

Akenson D.H. (1970) The Irish Educational Experiment: The National System of Education in Ireland in the Nineteenth Century, London: Routledge and Keegan Paul.

Bain, G. (2006) Schools for the Future: Funding, Strategy, Sharing: Report of the Independent Strategic Review of Education. https://dera.ioe.ac.uk/9777/1/review_of_education.pdf.

Belfast Telegraph (2019) '22 Northern Ireland schools could close because of 'sustainability issues', 17 June 2019, https://www.belfasttelegraph.co.uk/news/northern-ireland/22northern-ireland-schools-could-close-because-of-sustainability-issues-38225556.html.

Berger R., Abu-Raya, H. and Gelkopf, M. (2015) The Art of Living Together: Reducing Prejudicial Attitudes through the Arab-Jewish Class Exchange Program. Educational Psychology, 107: 678-698.

Borooah, V., and Knox. C. (2015) The Economics of Schooling in a Divided Society: The Case for Shared Education. Basingstoke: Palgrave Macmillan.

Borooah, V. and Knox, C. (2013) The contribution of 'shared education' to Catholic-Protestant reconciliation in Northern Ireland: A third way? British Educational Research Journal, 39 (5): 925-946.

Braun, V. and Clarke, V. (2006). Using thematic analysis in psychology. Qualitative Research in Psychology, 3: 77-101.

Carlisle, K., and Hughes, J. (2013) The role of inter-school collaboration in promoting intergroup relations: The Northern Ireland perspective. In: Biseth, H. and Holmarsdottir, H. (Eds.) Human Rights in the Field of Comparative Education (pp. 125-145). Sense Publishers.

Connolly, P., Hanratty, J., Hughes, J., Chapman, C. and Blaylock, D. (2019) PROTOCOL: Protocol for a systematic review: Inter-school collaborations for improving 
educational and social outcomes for children and young people. The Campbell Collaboration, 15: e1011, https://doi.org/10.1002/c12.1011.

Department of Education NI (2015) Sharing Works: A Policy for Shared Education. https://www.education-ni.gov.uk/publications/sharing-works-policy-shared-education. Department of Education NI (2009) Schools for the Future: A Policy for Sustainable Schools. https://www.education-ni.gov.uk/sites/default/files/publications/de/a-policy-forsustainable-schools.pdf.

Devecchi, C. and Rouse, M. (2010), An exploration of the features of effective collaboration between teachers and teaching assistants in secondary schools. Support for Learning, 25: 91-99, https://doi.org/10.1111/j.1467-9604.2010.01445.x.

Duffy and Gallagher (2015) Collaborative evolution: the context surrounding the formation and the effectiveness of a school partnership in a divided community in Northern Ireland, Research Papers in Education, 30 (1): 1-24, https://doi.org/10.1080/02671522.2014.880731.

Duffy, G. and Gallagher, T. (2017) Shared education in contested spaces: collaborative networks improve communities and schools, Journal of Educational Change, 18 (1): 107-134.

Fontana, G. (2016) Education Policy and Power-Sharing in Post-Conflict Societies: Lebanon, Northern Ireland, and Macedonia. Switzerland: Palgrave Macmillan

Gallagher, T. (2016) Shared education in Northern Ireland: school collaboration in divided societies, Oxford Review of Education, 42 (3): 362-375.

Gardner (2016) Education in Northern Ireland since the Good Friday Agreement: Kabuki theatre meets danse macabre, Oxford Review of Education, 42 (3): 346-361, https://doi.org/10.1080/03054985.2016.1184869.

Hansson, U., O’Connor-Bones, U and McCord, J. (2013) Integrated education: a review of policy and research evidence 1999-2012. Report commissioned by the Integrated Education Fund. http://cain.ulst.ac.uk/issues/education/docs/ief_2013_report_unesco.pdf.

Hewstone, M. and Hughes, J. (2015) Reconciliation in Northern Ireland: The Value of Intergroup contact, BJPsych International, 12 (3): 65-67.

Hill, K. (2011) Possibilities for social cohesion in education: Bosnia-Herzegovina, Journal, Peabody Journal of Education, 86 (92): 155-170. 
Hughes J., Lolliot S., Hewstone M., Schmid K. and Carlisle K. (2012) Sharing Classes between Separate Schools: a mechanism for improving inter-group relations in Northern Ireland? Policy Futures in Education, 10 (5): 528-539.

Hughes, J. and Loader, R. (2015) 'Plugging the gap': shared education and the promotion of community relations through schools in Northern Ireland, British Educational Research Journal, 41 (6): 1142-1155.

Hunter, A., Bates, J., McCully, A. and O'Connor-Bones, U. (2014) Report on the Shared Teacher role in the PIEE project. Ulster University School of Education Report for the North-Eastern Education and Library Board.

Hunter, A., Bates, J., McCully, A. and O'Connor-Bones, U. (2012) Evaluation of the Primary Integration / Enriching Education (PIEE) Project: A Legacy of Partnership. Ulster University School of Education Report for the North-Eastern Education and Library Board.

Hunter, A., Bates, J., McCully, A. and O'Connor-Bones, U. (2011) 'Half-stranger, halffriend': Research on the Primary Integration / Enriching Education (PIEE) Project. Ulster University School of Education Report for the North-Eastern Education and Library Board.

McKeever, C., Bates, J. and Reilly, J. (2017) School library staff perspectives on teacher information literacy and collaboration. Journal of Information Literacy, 11 (2): 51-68. https://ojs.lboro.ac.uk/JIL/article/view/PRA-V11-I2-3.

Milliken, M., Bates, J. and Smith, A. (2020) Education policies and teacher deployment in Northern Ireland: ethnic separation, cultural encapsulation and community crossover, British Journal of Educational Studies, 68 (2): 139-160, https://doi.org/10.1080/00071005.2019.1666083.

Muijs, D. (2015) Improving schools through collaboration: a mixed methods study of schoolto-school partnerships in the primary sector. Oxford Review of Education, 41 (5): 1-24.

Mulholland, M. and O'Connor, U. (2016) Collaborative classroom practice for inclusion: perspectives of classroom teachers and learning support/resource teachers, International Journal of Inclusive Education, 20 (10): 1070-1083, https://doi.org/10.1080/13603116.2016.1145266.

Murray, D. (1985) Worlds Apart: Segregated Schools in Northern Ireland. Belfast: Appletree Press. 
Murtagh B. (2003) Territoriality, Research and Policy Making in Northern Ireland, O. Hargie and D. Dickson (eds.), Researching the Troubles: Social Science Perspectives on the Northern Ireland Conflict, Edinburgh: Mainstream Publishing, pp.209-225.

Niens U., Cairns E. and Hewstone M. (2003) O. Hargie and D. Dickson (eds.), Researching the Troubles: Social Science Perspectives on the Northern Ireland Conflict, Edinburgh: Mainstream Publishing.

Northern Ireland Audit Office (2015) Department of Education: Sustainability of Schools. Belfast: Northern Ireland Audit Office.

O'Connor, U., Hartop, B. and McCully, A. (2002) A review of the schools community relations programme. Department of Education, Northern Ireland.

Payes, S. (2013) Separate education and hegemonic domination: civil society challenges in the Arab-Jewish city of Jaffa, Intercultural Education, 24 (6): 544-558.

Perry, C. (2011) Sharing and collaborating in education. Northern Ireland Assembly Research and Information Service Briefing Paper, Paper 165/11. http://www.niassembly.gov.uk/globalassets/Documents/RaISe/Publications/2011/Edu cation/16511.pdf.

Perry, C., Love, B. and McKay, K. (2017) Composite classes. Northern Ireland Assembly Research and Information Service Briefing Paper, Paper 05/17. http://www.niassembly.gov.uk/globalassets/documents/raise/publications/20162021/2017/education/0517.pdf.

Pro.Ed Consulting (2013) Evaluation of the Fermanagh Shared Education Programme Teacher Exchange Scheme (Shared Teachers). Enniskillen: The Fermanagh Trust. http://www.fermanaghtrust.org/images/custom/uploads/127/files/Evaluation\%20of\%2 0Fermanagh\%20Teacher\%20Exchange\%20Scheme\%20Report.pdf.

Richardson N. (2011) Formation: The Roots of Education for Diversity and Mutual Understanding, N. Richardson and T. Gallagher (eds.) Education for Diversity and mutual Understanding: the Experience of Northern Ireland, Bern: Peter Lang, pp. 91116.

RSM McClure Watters (2014) Evaluation of the Sharing Education Programme. Programme Level Summative Evaluation Report (Year 1-3), Final Report. http://www.sepni.org/resources/6287/6428_6287_77_Evaluation_of_the_Sharing_Ed ucation_Programme.pdf.

Smith, A. and Hansson, U. (2015) A review of policy areas affecting integration of the education system in Northern Ireland. The Integrated Education Fund. IEF, Belfast. 
https://www.ief.org.uk/wp-content/uploads/2011/08/Integrated-Education-ScopingPaper.pdf.

Smith, A. (2001) Religious segregation and the emergence of integrated schools in Northern Ireland. Oxford Review of Education, 27(4): 559-75.

Smith, A. (2014) Contemporary challenges for education in conflict affected countries. Journal of International and Comparative Education, 3 (1). pp. 113-125.

Šūpule, I. and Søholt, S. (2019) Rural municipalities and change in local school structure: Comparing room for manoeuvre among rural municipalities in Latvia and Norway, Scandinavian Journal of Educational Research, 63 (7): 1070-1085, https://doi.org/10.1080/00313831.2018.1476916.

Svanbjörnsdóttir, B. M., Macdonald, A., \& Frímannsson, G. H. (2016). Views of learning and a sense of community among students, paraprofessionals and parents in developing a school culture towards a professional learning community. Professional Development in Education, 42 (4): 589-609, https://doi.org/10.1080/19415257.2015.1047037.

Todman, P., Harris, J., Carter, J. and McCamphill, J. (2009) Better together: Exploratory case studies of formal collaboration between small rural primary schools. An Eastern Leadership Centre Report. Research Report DCSF-RR162, Department of Children, Schools and Families, http://dera.ioe.ac.uk/id/eprint/11072.

Valli, L., Stefanksi, A. and Jacobson, R. (2016) School-community partnership models: implications for leadership, International Journal of Leadership in Education: Theory and Practice, 21 (1): 31-49, https://doi.org/10.1080/13603124.2015.1124925.

Vangrieken, K., Dochy, F., Raes, E. and Kyndt, E. (2015) Teacher collaboration: A systematic review, Educational Research Review, 15: 17-40.

Yin, R. K. (2006) Mixed methods research: Are the methods genuinely integrated or merely parallel? Research in the Schools, 13 (1): 41-47.

Young, O. (2013) Identifying potential for sharing education in interface areas. A Report for the Institute of Conflict Research; Integrated Education Fund; and Belfast Interface Project, https://www.belfastinterfaceproject.org/sites/default/files/publications/Sharing\%20Ed ucation\%20in\%20Interface\%20Areas.pdf.

Zembylas, M. (2010) Pedagogic struggles to enhance inclusion and reconciliation in a divided community, Ethnography and Education, 5 (3): 277-292. 